\title{
Los inicios de la contabilidad municipal en Castilla. Paredes de Nava (1386-1396)
}

\author{
María Jesús Fuente*
}

\begin{abstract}
RESUMEN
La necesidad de iniciar libros de cuentas para la buena administración financiera de los municipios medievales ha sido estudiado para las ciudades de algunos ámbitos europeos, especialmente para el ámbito francés. La Guerra de los Cien Años, con sus costes de mantenimiento de un buen sistema de fortificaciones, parece el motor principal de una contabilidad escrupulosa. En los reinos de la Península lbérica no se encuentra una causa tan clara y rotunda, pero los indicios apuntan en el mismo sentido, es decir, a que fuera la necesidad de mantener las murallas en buenas condiciones por los peligros de las guerras, y la fiscalidad subsiguiente, 10 que llevó al inicio de los libros de cuentas municipales. A través del ejemplo de la villa de Paredes de Nava se estudia la forma de organizarse esta primitiva
\end{abstract}

\section{ABSTRACT}

On the basis of scholarly studies of Medieval France, it seems clear that the origins of municipal book-keeping can be traced to the outbreak of the Hundred Years War and the need of building an strong system of fortifications. Whether this is also true in the kingdoms of the Iberian Peninsula is less clear, but the evidence suggests that there too municipal book-keeping arose out of the need to maintain walls for purposes of defense and to finance their maintenance. By examening the town of Paredes de Nava and its early municipal accounts, this article suggests that there are very few significant differences in municipal book-keeping between French cities and lberian ones.

* Universidad Carlos III. 
administración contable, viéndose que

no se encuentran diferencias

significativas entre las cuentas

municipales del Reino de Castilla y las

de otras ciudades del Occidente

europeo.

A pesar del interés que el estudio de la ciudad medieval ha despertado en los últimos tiempos, $y$ de haberse publicado muchas monografías, hay un aspecto que, sin haberse olvidado, necesita de mayor profundización: se trata del funcionamiento financiero de ciudades y concejos en la Edad Media '.

El estudio de las finanzas urbanas requiere una fuente fundamental: los libros de cuentas que mantenían los encargados de la hacienda? ${ }^{2}$. Aunque no siempre tan explícitas como cabría esperar, las cuentas muestran una organización contable bastante bien delimitada. En efecto, el mantenimiento de libros de cuentas sugiere la existencia de una contabilidad más o menos bien llevada. Al hablar de contabilidad nos estamos refiriendo al mantenimiento de los libros de cuentas de los oficiales encargados de las finanzas concejiles. $Y$ aquí se plantea la primera cuestión de este artículo: ¿desde cuándo se encuentran libros de cuentas o una contabilidad organizada?

Es obvio que desde su más primitiva organización, los concejos tenían unos gastos, para los que necesitaban proveerse de unos ingresos, luego la organización financiera se remonta al momento de fundación de los municipios ${ }^{3}$. No es mi intención aquí hablar de la formación de las haciendas municipales, objeto ya de algunos estudios ${ }^{4}$, sino en concreto de las pri-

- Apuntaban la laguna en la historiografía francesa en el campo de las finanzas de las ciudades medievales, J. Glenisson y Ch. Higounet, "Remarques sur les comptes et sur l'administration financière des villes françaises entre Loire et Pyrénées (xIve-xvie siècles)", Finances et comptabilité urbaines du xille au XVI siecle, Coloquio Internacional de Blankenberge, 1962, Bruselas, $1964,31-51$.

2 Sobre las fuentes documentales para estudiar las finanzas urbanas, D. MENJOT y M. SÁNCHEZ (coord.), La fiscalité des villes au Moyen Age. (France méridionale, Catalogne et Castille). 1. Etude des Sources, Privat, 1996.

3 B. BARBADORO, Le finanze della repubblica fiorentina. Florence, 1929, 1. Indica que los orígenes de las finanzas son una misma cosa con el origen de la comuna.

4 I. Álvarez de Cienfuegos, "Notas para el estudio de la formación de las haciendas municipales", Homenaje a D. Ramón Carande, Madrid, 1963, II, 3-19. A. COLLANTES DE TERAN, "La formación de las haciendas locales en el Reino de Granada", Estudios sobre Málaga y el Reino de Granada en el V Centenario de su conquista, Málaga, 1987, y “Alfonso X y los Reyes Católicos: la formación de las haciendas municipales", En la España medieval, 13, 1990, 253-270. 
meras cuentas municipales, de la época en que surgieron, de las posibles razones para su aparición, y de su funcionamiento más primitivo o inicial.

Los primeros libros de cuentas concejiles conservados en la Península Ibérica se remontan al siglo XIV y se encuentran en el reino de Aragón. En concreto los primeros son catalanes: la primera serie de cuentas conservadas se inicia en Cervera en 1333, le sigue después Reus, donde se encuentran series anteriores a 1350, Puertomingalvo (provincia de Teruel) con una primera cuenta fechada en 1356, Valls con su primera cuenta de 1357 y Zaragoza de 1368.

Los primeros libros de cuentas del reino de Castilla se fechan en la segunda mitad del siglo xIV. La serie de los libros de mayordomazgo de Sevilla se inicia en 1368 , la de los procuradores del concejo de Paredes de Nava en 1386, Murcia conserva cuentas de 1391, Piedrahita de 1413, Palencia de 1432, Benavente de 1433, Zamora de 1484, etc. Probablemente otras localidades tuvieran también libros de cuentas para estas fechas, pero se han perdido, de la misma manera que algunos de los lugares citados probablemente los mantuvieran antes de las fechas señaladas.

En la primera anotación de cuentas conservada en Paredes de Nava, fechada el 8 de mayo de 1386, se cita a un vecino que "comienço a pagar desde la carta nueva que son que se dio en el mes de jullio que paso de 1385 fasta primer dia de junio deste año de 1386". La mención a la "carta nueva" apunta a la existencia, probablemente desde hacía tiempo, de una organización de la hacienda en la que los bienes raíces eran valorados de acuerdo con unos patrones. En efecto, la organización de la hacienda, con unos ingresos provenientes de impuestos directos sobre los hogares (el fumazgo), los bienes inmuebles (la raíz) y el ganado (el mueble), aparece tan configurada en este primer documento conservado, que es difícil admitir que fuera esta la primera vez que se redactaba la cuenta. En efecto, no sería arriesgado afirmar que no era este el primer año en el que se tomaban las cuentas, ni siquiera el primer año en el que se anotaban, y que, por el contrario, el mecanismo de organización de la hacienda se había iniciado años atrás.

Si no es fácil datar con precisión el comienzo de la contabilidad municipal, es aún más difícil conocer las razones para el mantenimiento detallado y meticuloso de las cuentas concejiles. Porqué se inicia la contabilidad y porqué en esa época en concreto son, pues, dos cuestiones obvias. El mantenimiento de la contabilidad representó un paso importante en la administración de los municipios, y en ese sentido es interesante buscar respuestas a las preguntas planteadas en diversos concejos, en concreto en concejos que conserven las cuentas más antiguas, pues los concejos 
que no conservan sus primeras cuentas no permiten conocer las preocupaciones iniciales que llevaron a inscribir las cuentas ${ }^{5}$.

Como contribución a la búsqueda de respuestas nos proponemos en este artículo el estudio de la contabilidad inicial de un concejo castellano, Paredes de $\mathrm{Nava}^{6}$, seleccionado fundamentalmente por dos razones: en primer lugar por conservar uno de los documentos contables más antiguos del reino de Castilla, el de 1386, y en segundo lugar por su excelente serie, desde 1386 hasta el final del siglo se conservan parcialmente las cuentas de los años 1388 a 1400, faltando sólo datos de los años 1387 y 1397.

\section{¿POR QUÉ SE INICIA LA CONTABILIDAD CONCEJIL A MEDIADOS DEL SIGLO XIV?}

No es sólo en la Península Ibérica donde se fechan los primeros libros de cuentas en la segunda mitad del siglo xIV, en otros ámbitos europeos, concretamente en Francia, las primeras cuentas conservadas también se remontan a mediados de ese siglo. Excepcionalmente algunas ciudades francesas, como algunas catalanas, han conservado cuentas de la primera mitad del Trescientos, pero la mayoría están fechadas en la segunda mitad de este siglo ${ }^{7}$.

La aparición de los primeros documentos contables en la Península Ibérica y Francia desde mediados del siglo xIV aproximadamente, lleva a pensar que esta fecha no es un simple resultado del azar. Las razones para la necesidad de mantener una contabilidad detallada parecen claras para el país vecino: las vicisitudes de la Guerra de los Cien Años hicieron precisa la mejora del sistema defensivo, y con ello unos gastos más elevados en el cuidado o mejora de las fortificaciones ${ }^{8}$. La inseguridad provocada por la Guerra de los Cien Años promovió la necesidad de gastar

\footnotetext{
I. Álvarez de Cienfuegos, “Notas para el estudio de la formación de las haciendas», 23, considera la época de mediados del siglo xiv como la tercera etapa en la organización de las haciendas municipales.

6 La villa de Paredes de Nava se encuentra situada en la actual provincia de Palencia, a unos 20 kilómetros de la capital, en la comarca de la "Tierra de Campos". Fue un concejo de señorío durante la mayor parte de los siglos XIV y XV, siendo uno de sus señores más destacados D. Fernando de Antequera. No debió superar los 5.000 ó 6.000 habitantes de población, pues el número de pecheros nunca llegó a los 1.000. Sobre este concejo ha elaborado un interesante trabajo J. C. MARTIN CEA, El mundo rural castellano a fines de la Edad Media. El ejemplo de Paredes de Nava en el siglo XV. Valladolid, 1991

J. Glenisson y Ch. Higounet, "Remarques sur les comptes", 36

8 Ibid., 43
} 
dinero en las murallas. No podía haber buenas murallas sin dinero. El peso de la construcción recaía sobre los municipios que, al sentirse agraviados, exponían sus quejas en el Parlamento de París.

El consenso casi general de que existe una relación entre gastos de fortificación y desarrollo de la contabilidad municipal, quedó de manifiesto en el Coloquio Internacional de Blankenberge de 1962, en el que algunos historiadores afirmaron que hubo ciudades francesas que por su situación geográfica no estuvieron afectadas por la Guerra de los Cien Años, y que también sus primeros gastos estaban relacionados con la defensa. Así las primeras cuentas de la ciudad de Namur, de 1362, anotan dos tercios de las partidas para afrontar los gastos militares ${ }^{9}$. La necesidad de dinero para hacer frente a los gastos de guerra es lo que llevó a la necesidad de imponer unos impuestos, de los que una de sus consecuencias es el inicio del mantenimiento de libros de cuentas ${ }^{10}$. El lazo de unión entre inicios de la contabilidad y gastos de defensa se pone de manifiesto al ser el receptor de las cuentas el encargado de supervisar los trabajos públicos ${ }^{11}$.

El argumento de que la necesidad de emplear dinero público para el mantenimiento de la muralla, lleva a una más cuidadosa administración de ese dinero, va acompañado de la idea de que en Francia, la Guerra de los Cien Años tuvo un papel evidente en el desarrollo de las libertades municipales. En los nuevos gobiernos de las ciudades se daría entrada a unos ciudadanos que controlarían algunos de los aspectos de la vida de la ciudad, pero que, al mismo tiempo, pretenderían dar pruebas de honestidad y desinterés, de lo que no podian dar mejor muestra que manteniendo una contabilidad de las finanzas del municipio de forma detallada y escrupulosa.

Las causas económicas no están ausentes, entre ellas la crisis provocada por la Peste Negra, considerado como un agravante, en el sentido de que si había que levantar fortificaciones o realizar trabajos de reparación, se hacía en un momento en que se había producido una subida de precios $y$ de salarios ${ }^{12}$. Estas repercusiones económicas contribuirian a la necesidad de mantener una contabilidad minuciosa.

Estas posibles causas del inicio de la contabilidad municipal, que parecen claras para el área francesa, podrian ser aplicadas al caso hispano,

9 Finances et comptabilité urbaines du xille au xvie siecle, 68.

10 B. Chevalier en "La fiscalité urbaine en France, un champ d'expérience pour la fiscalité d'État", Col-Joqui Corona, municipis i fiscalitat a la Baixa Edat Mitjana, Lleida, p. 70.

J. GLENISSON y Ch. HIGOUNET, "Remarques sur les comptes", 46.

12 Finances et comptabilité urbaines du xille au xvie siecle, 69. 
aunque en la Península lbérica esas razones no están tan claras. En principio, las cuentas de los concejos hispanos presentan muchas similitudes formales con las francesas, incluso algunos de los gastos efectuados en la mayoría de los concejos, reflejados en las primeras cuentas conservadas, están también en relación con la mejora de la cerca ${ }^{13}$. Esta búsqueda de șimilitudes podría conducir a la búsqueda de conflictos que, como en Francia, hicieran necesario el refuerzo del sistema defensivo.

En algunos municipios catalanes se ha puesto de manifiesto el binomio guerra/fiscalidad y su consecuencia de desarrollo de las cuentas municipales por el interés de mantener cuidadosamente las cuentas fiscales ${ }^{14}$. El reino de Castilla no estuvo exento de conflictos internos durante el siglo XIV: en la primera mitad los problemas durante la minoría y el reinado de Alfonso XI, y en la segunda mitad el enfrentamiento entre sus hijos Pedro I y Enrique II, entrentamiento que, por otra parte, involucró a los dos bandos en lucha en la Guerra de los Cien Años. Previamente Pedro I había estado en guerra con Pedro IV el Ceremonioso, de quien se sabe que hizo una petición en las Cortes de Cariñena de 1357, solicitando armar 700 caballeros, para frenar la invasión de Aragón por parte de los castellanos y su rey Pedro I ${ }^{15}$.

Esos conflictos, junto a las banderias y luchas internas de la nobleza, condujeron en el caso castellano a trabajos de construcción o reparación de murallas ${ }^{16}$. Esas obras representaban un peso económico para las ciudades, que, como en el caso francés, también ha quedado de manifiesto en los cuadernos de Cortes. En concreto en las Cortes de Madrid de 1329 se presentaron las quejas de la pérdida del privilegio concedido a las ciudades por los reyes castellanos y por la regente María de Molina que consistía en recibir algunos derechos de rentas, impuestos o derechos reales para el mantenimiento de elementos defensivos, derecho que restituyó Alfonso $\mathrm{XI}^{17}$. Sin embargo, las ciudades debían estar acostumbradas a

13 La primera anotación de las cuentas conservadas en Paredes de Nava es la cuenta de un fumazgo derramado "para la cerca".

14 M. SANCHEZ Y P. ORTi, "La Corona en la génesis del sistema fiscal municipal en Catalunya (1300-1360)", Col-loqui Corona, municipis i fiscalitat a la Baixa Edat Mitjana, p. 245.

15 E. SARASA, “La incidencia del patrimonio real en el tejido social aragonés durante la Baja Edad Media», Colloqui Corona, municipis i fiscalitat a la Baixa Edat Mitjana, pp. 353-354.

16. En León se construyó una cerca de cal y piedra en el siglo xIv. C. EsTEPA, Estructura social de la ciudad de León (siglos xi-Xiii), León, 1977, 143. Afirma el autor que "no es extraño que estas obras tengan lugar en un momento en que la organización concejil está completamente desarrollada y en un periodo de disturbios que enfrentan la oligarquía municipal con la alta nobleza".

17 Cortes de los antiguos reinos de León y de Castilla, 1, 419. Un ejemplo de que las ciudades retenían algunos impuestos reales para mantenimiento de la muralla, se encuentra en la ciudad de 
hacerse cargo de los gastos de fortificaciones, que se habían planteado mucho antes; ya Alfonso $X$, en las Siete Partidas, había indicado la manera de sufragar los gastos para murallas, puertas u otros elementos defensivos, haciéndolos recaer sobre las finanzas de las ciudades ${ }^{18}$.

Con motivo de la guerra fratricida, también se encuentran quejas en los cuadernos de Cortes en relación con los gastos extraordinarios para reparación de murallas u otros elementos defensivos. En concreto en las Cortes de Burgos de 1367 aparece la queja de Toledo que pide ayuda para «emienda delas tomas e rrobos e del mal e dapno que rresçibieron delos françeses, por lo qual tienen sus heredades desalinnadas e desrreparadas" ${ }^{19}$, y más especificamente reclama del rey las rentas de algunos lugares que le habían sido concedidos a la ciudad para tener algunos propios, y «dar delo nuestro (del Rey) alguna quantía de mr.», ambas cosas "para labrar los muros de Toledo que estan mucho desrreparados" y "era mucho mester para guardar la çibdat para nuestro seruiçio» ${ }^{20}$. El caso de Toledo podría repetirse en otras ciudades, aunque no aparezca reflejado en los cuadernos de Cortes.

La organización política municipal también influyó, como en el caso francés, en la necesidad de una mejor organización contable en los municipios. En el caso hispano, y concretamente castellano, si no se puede hablar exactamente de desarrollo de las libertades municipales como consecuencia de una guerra, hay que señalar que se producen cambios significativos en la organización municipal que pueden explicar la necesidad de mantener una contabilidad más rigurosa ${ }^{21}$. Esos cambios se centran

Burgos, que en 1292 retenía la fonsadera, unos 50.000 maravedies, para la "labor de sus muros", M. A. Ladero Quesada, Fiscalidad y poder real en Castilla, (1252-1369), Madrid, 1993, 44.

18 Partida III, título XXXII, ley XX "Cómo los castiellos, et los muros de las villas, et las otras fortalezas, et las calzadas, et las puentes et los caños de las villas se deben mantener et reparar. ...si en las cibdades ó en las villas do han meester de facer algunas destas labores, si han rendas apartadas de comun, deben hi seer primeramente despendidas: et si non complieren 6 non fuese hi alguna cosa comunal, entonce deben los moradores de aqquel logar pechar comunalmiente...". El mantenimiento de los muros a costa de las ciudades se pone de manifiesto en León, cuando en 1315 solicita del rey una alcabala upara çerca de la villa en llogares çiertos que lo auia mucho mester", C. ESTEPA, León (siglos Xi-xiI), 143, nota 185. Como la alcabala era un impuesto real, podría considerarse esta petición de León como una situación intermedia: el concejo impone a sus ciudadanos una carga que correspondería al rey, pero que éste no había impuesto. De esa forma sale de las arcas de los vecinos el dinero para la cerca, pero podría interpretarse como una concesión real.

19 Cortes de León y Castilla, II, 159.

20 Cortes de León y Castilla, II, 161.

21 I. Álvarez de Cienfuegos, "Notas para el estudio de la formación de las haciendas", 23, atribuye a irregularidades administrativas, junto a las turbulencias políticas, la necesidad de reorganizar la hacienda municipal. 
fundamentalmente en la organización del Regimiento por Alfonso XI a mediados del siglo XIV.

En algunas de las ciudades en las que se llevó a efecto la reforma municipal de este monarca, en concreto en Zamora (1342) y en Burgos (1345), la ordenanza indicaba que los oficiales del concejo «ayan poder conplidamente para administrar todas las rentas de los comunes de la dicha çibdad recabdandolos e faziendolos recabdar" ${ }^{22}$. En el Ordenamiento que otorgó a Algeciras (1345) establecía que el gobierno municipal estaría en manos de "doze cavalleros e omes buenos" y de "quatro fieles que avedes de aver fazienda de la dicha çibdat", junto a ellos habia otros oficiales, entre los que se encontraba un mayordomo. La puesta en marcha de esa organización hacendística concejil requería, sin duda, una organización más cuidada, en la que se enmarcaría el inicio de la contabilidad municipal anotada en libros especialmente habilitados para ella.

La obra de Alfonso XI en lo referente a la administración de las haciendas concejiles, probablemente consistió en sistematizar algunos aspectos que ya venían desarrollándose con anterioridad. El rey, en su intento de controlar el gobierno municipal, estableció oficiales que se encargaran de manera sistemática de la administración financiera de los concejos. Esta era la novedad, el control por parte de unos oficiales, porque la organización financiera existiria desde el momento que existía un concejo, de manera que no seria arriesgado afirmar que la obra de Alfonso $\mathrm{XI}$ se limitó a asegurar que «la costumbre se hiciera ley». Como consecuencia las finanzas municipales comenzaron a controlarse de manera más próxima y sistemática, y para ello se necesitaba mantener una contabilidad escrita lo más clara y detalladamente posible.

La actividiad legislativa de Alfonso XI, y en particular la creación del Regimiento, podría considerarse, pues, como una razón de peso. Con la imposición del Regimiento, los concejos empezaron a tener una organización más formal y burocrática, y eso les obligó a dejar constancia de sus decisiones en los libros de actas concejiles y de cuentas municipales. La cbligación de presentar relación de ingresos y gastos al rey y al señor, les empujó a mantener una contabilidad más rigurosa, para poder dar cuentas de su gestión en caso de ser requeridas.

22 Ordenanzas del concejo de Burgos, J. A. BonachiA, El concejo de Burgos en la Baja Edad Media (1345-1426), Valladolid, 1978, 151. Es casi exactamente igual el texto de las ordenanzas de Zamora, M. F. LADERo Quesada, La ciudad de Zamora en la época de los Reyes Católicos, Zamora, 1991, 182. 
Por último, en los inicios de la contabilidad municipal no dejarían de tener un papel significativo los malos tiempos que sacudieron a los reinos hispánicos al traspasar el ecuador del siglo XIV. En las Cortes de Burgos de 1367 se expone la situación por la que pasaba el reino de Castilla en las décadas de 1350 y 1360 , y se indican las repercusiones financieras y fiscales de tal situación: "...por quanto toda la tierra está despoblada e muy yerma por esta mortandad postrimera que agora passó, por estas guerras que son passadas con los grandes pechos que ovieron a pechar, que está toda la tierra muy desegualada de los pecheros" ${ }^{23}$.

Como causas adicionales algunos estudiosos han señalado, para algunos países europeos, la mejor posibilidad de utilizar el papel, más asequible desde mediados del siglo XIV por el descenso de precio ${ }^{24}$, o en la mejor preparación de los encargados de las cuentas ${ }^{25}$, no hay constancia documental para que esas mismas razones puedan ser argumentadas en el caso hispano.

A estas causas que relacionan el caso hispano con el francés, habría que añadir otras razones puramente hispanas, o castellanas, que condujeran a los concejos a la necesidad de mantener una buena contabilidad. Una de las razones que habría que tener en cuenta es la del incremento de la presión fiscal al llegar al trono los monarcas de la casa Trastamara ${ }^{26}$, que obligaron a los municipios a contribuir más a las arcas reales, lo que induciría a las nuevas autoridades concejiles a poner más cuidado en las finanzas que tenían entre manos.

Para tratar de ver si en las primeras cuentas hay indicios de porqué se inicia la contabilidad, vamos a estudiar las cuentas mencionadas del concejo de Paredes de Nava, en concreto las de los diez primeros años, para ver si pueden ofrecer alguna luz sobre las cuestiones planteadas.

23 Cortes de León y Castilla, II, 147.

$24 \mathrm{M}$. BOUDET, Registres consulaires de Saint-Flour en langue romane avec résumé français (1376-1405), París, 1900, XI. El descenso del precio del papel ha sido documentado por A. Mackay entre 1390 y 1395 , basándose en las cuentas del mayordomo de Sevilla, el precio de la resma descendió de 62 maravedíes a 48, pero volvió a subir a 59,4 en 1396, y a 71 maravedíes en 1397. A. Mackay, Money, Prices and Politics in Fifteenth-century Castile, London, 1981, 141. En Paredes de Nava hay noticias del precio del papel para los años 1389 y 1411: la mano de papel costaba 3,5 maravedíes en 1389 y 11 o 12 en 1411, aunque el incremento no es real, pues en 1389 se trataría de maravedies viejos, en tanto que en 1411 serían maravedíes nuevos, con un valor de la mitad de los viejos.

25 J. GLENISSON y Ch. Higounet, «Remarques sur les comptes", 38.

26 M. A. LADERO QUESADA, Fiscalidad y poder real en Castilla e "Ingreso, gasto y política fiscal de la Corona de Castilla. Desde Alfonso X a Enrique III (1252-1406)", Hacienda Pública Española, $69(1981), 25-55$. 


\section{LAS PRIMERAS CUENTAS DE PAREDES DE NAVA}

¿En qué medida las primeras cuentas reflejan la necesidad de emprender una contabilidad minuciosa debido a los ordenamientos de Alfonso $X I$ ? ¿Qué se inscribe en las primeras cuentas que pudiera dar una idea del porqué de iniciar la contabilidad? Hay que fijarse en los datos anotados en esa documentación, y ver de qué les interesaba que quedara constancia.

La primera anotación de la contabilidad de Paredes de Nava es una derrama de fumazgo ${ }^{27}$ para hacer frente a los gastos de mantenimiento de la cerca. Además de los maravedies recaudados de cada barrio, se descuenta una cantidad para pagar al carpintero que se hizo cargo de los trabajos de los portillos que, presumiblemente, corresponderían a la parte de muralla de cada uno de esos barrios. En el capítulo de gastos aparecen otros trabajos de mantenimiento de las sobrepuertas. En conjunto, fuera una parte u otra de la muralla, parte del dinero recaudado iba para la defensa de la villa.

La cuenta de 1388 se limita a breves anotaciones sobre los pagos que han de realizar al conde, señor de la villa ${ }^{28}$. De 1389 sólo se conservan los gastos efectuados en la reparación de una puerta, y una larga data con gastos muy diversos entre los que destacan los pagos efectuados como consecuencia de las obligaciones del concejo hacia el señor y hacia el rey. De 1390 sólo se conserva la cuenta de las dos monedas. De 1391 la cuenta de las 5 monedas, otra referencia a las seis monedas, y una cuenta de la cebada y el vino que habian mandado al conde su señor. De ese mismo año es el documento de las condiciones de arrendamiento de las alcabalas de la villa. De 1392 sólo se ha conservado la cuenta que no pudieron coger los cogedores de las seis monedas.

Para conocer mejor la contabilidad en esta primera década hay que acudir a las cuentas de 1393 y 1394, que son las dos mejor conservadas. En efecto, está completo el «libro de las cosas que Pero Martines procurador del conçeio rresçebio e despendio por el dicho conçeio el ano de 1393 que fueron procuradores el dicho Pero Martines e Juan Martines Chaperete». Esta cuenta es la primera de la que se conserva la larga relación de pagos del procurador.

27 El fumazgo era un impuesto que gravaba los hogares de los pecheros. Este término servía también para designar la unidad de tributación. M. J. FUENTE, Finanzas y ciudades. El tránsito del siglo xv al XVl, Madrid, 1992, 75 y ss.

${ }_{28}$ Paredes de Nava era una villa de señorío durante estos años estudiados. En algunos mo. mentos del sigio xiv fue villa de realengo. MaRTín CEA, Op. Cit. p. 43 y ss. 
Cuadro 1. Los gastos del concejo de Paredes de Nava èn 1393

\begin{tabular}{lc}
\hline \multicolumn{1}{c}{ CONCEPTO } & CANTIDAD \\
\hline Viajes para resolver asuntos del concejo & $2.406 \mathrm{mrs} .6 \mathrm{~d}$. \\
Soldadas y pagos de servicios de diversa índole & $1.168 \mathrm{mrs}$. \\
Pleitos & $650 \mathrm{mrs}$. \\
Convites y reuniones del concejo o de los hombres buenos & $53 \mathrm{mrs} .5 \mathrm{~d}$. \\
Obras & $581 \mathrm{mrs} .4 \mathrm{~d}$. \\
Compras de cosas necesarias & $24 \mathrm{mrs} .5 \mathrm{~d}$. \\
Gastos de mantenimiento & $28 \mathrm{mrs} .8 \mathrm{~d}$. \\
Alquileres & $73 \mathrm{mrs}$. \\
\hline
\end{tabular}

Hubo otros dos gastos importantes, uno de 1.000 maravedies cuya letra ilegible hace difícil conocer su contenido, y otro de 2.000 que le pagaron a "Juan Sanches carniçero por mandado del conçeio porque demandava los quarenta mill maravedies del pedido". Para hacer frente a todos estos gastos, el procurador Pero Martines contó con una recaudación de 8.624 maravedíes y 7 dineros, junto a 48 cargas de trigo.

Pero Sanches, procurador del concejo desde junio de 1394 a la Çinquesma de 1395 presentó dos cuentas, la primera era una relación de ingresos y gastos de poca cuantía ${ }^{29}$, que podría considerarse como una cuenta auxiliar de la que le sigue, de no ser que aparece primero, y que la segunda cuenta comienza diciendo: "estos son los maravedies que yo Pero Sanches procurador del concejo resçibi en su nombre despues de la otra cuenta que esta escripta en el libro del concejo".

La segunda cuenta es mucho mayor, recibió el procurador 37.059 maravedíes y 6 dineros ${ }^{30}$, de los que gastó prácticamente todos. Se puede apreciar en estas cifras una diferencia considerable respecto a la cuenta del procurador del año precedente. La diferencia se debe a que este procurador tenía a su cargo la recaudación del dinero necesario para hacer frente a las cargas señoriales, y de esta manera tuvo que recaudar 2.500 maravedíes de cada barrio para completar los 20.000 maravedíes del pedido del conde, aunque indica en la primera cuenta que el señor había solicitado 25.000 maravedíes ese año. Pero no fue esa la única recaudación de los barrios. Como había que pagar al conde 3.600 maravedíes de "marzadga" y 600 de yantar, cada uno de los barrios tuvo que aportar 525 maravedíes más. Otros 500 más que solicitó

\footnotetext{
29 Todo el ingreso fue de 1.194 maravedies, y el gasto de 1.094 y 5 dineros.

3o Parece haber una pequeña equivocación en la cuenta, pues sumando todas las cantidades recibidas, el total asciende de 37.065 maravedies.
} 
el concejo a cada barrio no tuvieron un destino específico, como los indicados anteriormente.

Exceptuando la cuenta de 1386, que confirmaría la tesis de los historiadores que defienden la necesidad de mantener la contabilidad concejil para la reparación de la cerca u otros elementos defensivos de las ciudades, se puede comprobar que buena parte de la contabilidad del concejo de Paredes de Nava se dedica a anotar las obligaciones hacia el rey (monedas, pedido, alcabalas), o hacia el señor (pedido, marzadga y yantar, pagos en especie).

Un análisis más detallado de estas primeras cuentas puede aportar luz acerca de las necesidades financieras de la hacienda, y su consecuente reflejo en la contabilidad detallada.

\section{LA ORGANIZACIÓN FINANCIERA DEL CONCEJO EN LA DÉCADA 1386-1396}

Las cuentas que se conservan entre los años 1386 y 1396 ofrecen un panorama de los aspectos más significativos del funcionamiento de la hacienda municipal, a pesar de que ingresos y gastos aparecen indicados con patente irregularidad. Es probable que los capítulos de ingresos fueran bastante similares de unos años a otros, pero la falta de documentación no permite afirmar si el mismo tipo de ingresos se repetía todos los años o no, pues su ausencia puede deberse no a que no fueran siempre los mismos, sino a una pérdida de parte del libro de cuentas. Algo similar podria decirse de los gastos, aunque no fueran las mismas las personas que recibían los pagos, o aunque hubiera diferencias significativas entre unos años y otros, habría probablemente unos gastos fijos o unos capítulos de gastos más o menos previsibles. Hay que utilizar los «retazos" conservados de diferentes años para poder presentar un panorama, si no completamente exacto, al menos lo más preciso posible.

El año contable no era siempre el año natural, sino que comenzaba generalmente en el mes de junio, coincidiendo con la fiesta religiosa de la "Çinquesma" ${ }^{31}$. Las cuentas aparecen anotadas de forma que los ingresos aparecen globalmente, en tanto que los gastos se encuentran desmenuzados en los pequeños pagos que se efectuaban, por ello siempre es

\footnotetext{
${ }^{31}$ El procurador Pero Martines ejerció su cargo "desde el dia de çinquesma del año de 1393
} años que començo el mi ofiçio de la procuraçion fasta un año cumplido que fue dia de çinquesma ...". 
mucho más largo el capítulo de gastos que el de ingresos. Estos aparecen con más claridad cuando se encuentra la cuenta de la derrama de algún impuesto, y entonces su descripción ocupa también bastantes páginas. La lista de gastos del procurador de 1393 ocupa quince páginas, en tanto que la anotación de los ingresos sólo ocupa tres páginas.

Ya en el primer año conservado de las cuentas aparecen los oficiales municipales que se encargaban de ellas, los procuradores. Dos años después, en 1388, se menciona a los "ocho omes buenos que an de ver fasienda del conçejo". Los procuradores tenían como misión hacerse cargo de las cuentas del concejo, obtener los ingresos y hacer los pagos correspondientes, siguiendo siempre el mandato de los alcaldes y regidores del concejo, o en ocasiones siguiendo la orden directa emanada del señor de la villa, el conde de Paredes. Eran remurierados por su trabajo, tal como se indica ya en la cuenta de 1386, con un salario de 200 maravedíes por un año, tiempo en el que desempeñaban su oficio. Los ocho "omes buenos" representaban a los ocho barrios de la villa, y ejercian una función de supervisión de la hacienda, de los gastos e ingresos, por la que no recibían ninguna remuneración.

Una de las características de estas primeras cuentas conservadas es la falta de una contabilidad conjunta, es decir, no sólo cada uno de los procuradores mantenía su propia contabilidad, sino que cada uno efectuaba más de una cuenta. Esto podria afirmarse de la primera de las cuentas, la de 1386. Aunque se trata de una cuenta completa, en la que el procurador ha recibido unos ingresos con los que ha realizado los pagos correspondientes, sin embargo, no cabe duda que se trata de una cuenta parcial, en la que faltan otros ingresos y gastos. En la propia cuenta analizada se haIlan referencias a los impuestos que no aparecen en la cuenta, como alcabalas o monedas, o a gastos importantes, como los correspondientes a los derechos señoriales. También parece ser una cuenta parcial la del procurador de 1393, de manera que faltan buena parte de los ingresos y de los gastos. $Y$ esta presentación de cuentas parciales se confirma el año siguiente, cuando el procurador de 1394, Pero Sanches, presenta dos cuentas distintas.

\section{LA HACIENDA CONCEJIL. LOS GASTOS}

Como era norma de aquel tiempo, el municipio no elaboraba presupuesto, y los ingresos estaban en función de los gastos. Estos eran muy variados. En las primeras cuentas la relación de gastos no es exhaustiva, el escribano se limitaba a indicar las partidas más importantes, que en el 
caso estudiado podrían clasificarse en dos, la primera las obras de mantenimiento de la villa, bien en la muralla o en otras partes, y la segunda el pago de las cargas señoriales debidas al señor. Si el capítulo de gastos de mantenimiento varía de unos años a otros de forma considerable, y era difícil preverlo, el concejo sabía la cantidad con la que había de contribuir a las arcas señoriales, capítulo que lógicamente habría de variar con el tiempo. No faltaron, ya en 1386, los gastos originados por el pago a los oficiales concejiles, las ayudas a ia hermandad, o los viajes de mensajeros a resolver asuntos del concejo.

Sin duda el capítulo más importante de gastos era el relacionado con las gestiones de los problemas que se le presentaban al concejo. Una buena parte del dinero se empleaba en pagar a los mensajeros o a los encargados de solucionar esos problemas, que habían de pasar varios días en otras localidades. Aunque los gastos eran pequeños, se realizaban tantos viajes a lo largo del año que configuraban el capítulo de más peso en el total de los gastos concejiles. El pago era de unos 3 maravedíes por persona y día, y otros tres por la caballería que les llevaba. Sólo se les pagaban los gastos, no recibían dinero por el servicio prestado. Si a los gastos de viaje había que añadir el pago de abogados para la defensa del concejo, el pago era muy superior. Este debió ser el caso de Alfons García escribano, que en 1393 fue "a casa del rey por el conçejo a rescatar las cartas que tenian ganadas los arrendadores de las seys monedas..."; su costa ascendió a 823 maravedíes por 34 días que estuvo allá, lo que incluía sus propios gastos, el pago a un hombre que le acompañó, y algunos servicios en la corte. En este caso este escribano parece que dio una cuenta aparte con sus gastos en la corte del rey, pero no se encuentran indicados en las cuentas concejiles conservadas.

Junto a los gastos considerados estrictamente de viajes, hay otros pagos para continuar algunos de los pleitos en los que está envuelto el concejo, en concreto en 1393 se encuentran dos pagos, uno de 350 maravedies y otro de 300 para hacer frente a los gastos originados por el pleito del portazgo de Palencia.

También habría que incluir entre los gastos de viajes el mantenimiento de un mulo y una mula que tenía en propiedad el concejo para realizar estos desplazamientos, y no tener que pagar el alquiler de las caballerías. Es evidente que no era suficiente, pero es indicativo de lo importante que eran estos viajes. Los gastos de mantenimiento eran minúsculos. Siguiendo con el ejemplo de 1393, se encuentra un pago de 20 maravedíes al escribano porque "fiso de costa el mulo de concejo mientras estado en casa que non andudo camino para conçejo", otro de 28 dineros por 
herrar el mulo, y otro de 15 dineros para un cabestro de sedas para ese mulo.

El segundo gran capítulo de gastos lo constituían los pagos de soldadas y servicios realizados para el concejo. Las soldadas se pagaban anualmente o semestralmente a las personas que tenían a su cargo algunos de los oficios necesarios a la villa. El escribano recibía una soldada semestral de 165 maravedíes, el médico 100 maravedíes al año, al pregonero se le pagaba una cantidad para el vestuario, en concreto se le pago este año 100 maravedíes por ese concepto, aparte de otros 60 para el alquiler de su casa, el procurador recibía 200 maravedíes al año. También recibían un estipendio las personas encargadas de las guardas de las puertas, aunque estos pagos aparecen de forma irregular. En 1393 al que guardó la puerta de Gallegos le pagaron 86 maravedíes, a otro que "guardo la puerta de Sant Juan en verano e otro tiempo" 50 maravedíes, a los que guardaron la puerta de Fuentinoria les dieron 38 maravedies que equivalían al valor de 4 cargas de cebada, a un guarda "a la puerta de la Fuente con los guardas que y estavan por un dia" 15 dineros. Hay otro pago en relación con las guardas de las puertas «a los ocho barrios del pan de los aniellos para guardar las puertas de la villa a cada barrio cuatro cargas que son treinta y dos cargas".

A las soldadas normales de algunos de estos hombres se le añadía en ocasiones algún pago extraordinario, como el que se hace en varias ocasiones al escribano por redactar cartas o escrituras que posiblemente no estuvieran consideradas parte de su trabajo ordinario. Junto a estos gastos habría que incluir también las pequeñas costas de las reuniones concejiles o de los hombres buenos que tomaban las cuentas del concejo, pues se solía hacer un gasto de vino o fruta, generalmente insignificante.

Había además otros servicios que formaban parte de las obras de mantenimiento de la localidad, y que se han incluido en el capítulo de obras. Este capítulo era más bien poco importante, en 1393 representó alrededor de un $7 \%$ de los gastos totales.

Menos importante era aún el capítulo de compras, pues aparte de materiales de construcción, incluídos en el capítulo de obras, las otras compras que efectuaba el concejo eran tan insignificantes que en 1393 se redujeron a papel (10 maravedíes), cera para sellar (2 maravedíes y 5 dineros) o el cabestro de seda antes mencionado (15 dineros).

La cantidad más elevada que pagó el procurador este año de 1393 fue la de 2.000 maravedíes al carnicero Juan Sanches por el servicio al concejo "que demandava los quarenta mill maravedies del pedido". Esta importante cantidad se pagaba a alguno de sus señores, al rey 0 al conde. 
Aunque en esa cuenta no se incluye, el concejo tenía estas dos obligaciones anuales. Las cargas reales no eran fijas, pero las señoriales sí lo eran. Hay referencias al pago del pedido del conde en años anteriores y posteriores a esta fecha, y la cifra era de 20.000 maravedíes anuales, aunque unos años después, en 1402, el señor les pidió dos cantidades elevadas de pedido, 30.000 y 40.000 maravedíes. No sería arriesgado pensar que la cifra de 40.000 que demandaba el vecino antes citado, fuera el pedido que pretendía el conde en ese año de 1393, no sólo porque parece que la demanda que se menciona iría encaminada a liberarse de tan elevada cantidad, sino porque en el capítulo de ingresos se anota el pago de 2.000 maravedies que recibe el procurador de los barrios, porque se los han prestado a Juan Sanches carnicero, cuando fue a demandar los 40.000 del pedido, y se menciona, aunque no con claridad "nuestro señor el conde".

Pero el conde no se conformaba sólo con el pedido, tenía derecho al servicio, marzo y yantar, que aunque de menor cuantía, no dejaba de ser significativo ${ }^{32}$, aparte de regalos en especie en momentos concretos del año, por S. Andrés y en Navidad.

En resumen, se puede concluir que los pagos más importantes que efectuaba el concejo iban dirigidos al rey o al señor, y otros pagos como los de mensajeros, abogados u otros, venían requeridos por la necesidad de negociar con el rey o con el señor algunos de esos pagos. En conjunto el porcentaje más elevado de los gastos iba dirigido a cubrir las cargas reales y señoriales, y las necesidades concejiles representaban un porcentaje mínimo en comparación con esas cargas.

\section{LA HACIENDA MUNICIPAL. LOS INGRESOS}

En la década estudiada aparecen los impuestos como fuente fundamental de ingresos. La relación de ingresos que se ha conservado de 1386 indica que la financiación del concejo provino de la derrama de un fumazgo y de una derrama del mueble en los ocho barrios de la villa, aunque es probable que hubiera también derrama de monedas o de lo contrario no aparecería la lista de los clérigos que habian de contribuir en ellas ${ }^{33}$. En

32 En 1401 el señor cobró de marzo y yantar 4.200 maravedies, y al año siguiente de servicio y marzadga 24.200. Libro de cuentas de Paredes, año 1401-1402.

33 Pocas veces se encuentra a los clérigos como contribuyentes, a pesar de la presión ejercida por las comunidades locales para tratar de conseguirlo. J. FAVIER, Finance et fiscalité au Bas Moyen Age, Paris, 1971, 170 y ss. 
las cuentas de otros años no faltan las menciones a impuestos indirectos, especialmente la alcabala, o a préstamos de vecinos, como ocurrió en 1388 , cuando varios vecinos adelantaron el dinero necesario para pagar el vino y los lechones que el concejo había de enviar al señor, y luego se les pagó con dinero recaudado de las alcabalas. Tampoco faltaban los ingresos procedentes de bienes de propios que el concejo arrendaba, tal como aparece en la cuenta de Pero Martines, procurador de 1393.

Cuadro 2. Los ingresos del procurador de 1393, Pero Martines

\begin{tabular}{lc}
\hline \multicolumn{1}{c}{ FUENTE DE INGRESOS } & CUANTIA RECAUDADA \\
\hline - Tercios postrimeros de la renta de las "cueças" & 800 maravedíes \\
- Tercio primero del año 94 renta de las "cueças" & 328 mrs. y 4 corn. \\
- Renta de la veladoría del año 1393 & 149 maravedies \\
- Renta de los "aniellos" del concejo del año 1393 & 48 cargas de trigo \\
- Del alcance del procurador del año pasado & 956 maravedies \\
- De los ocho barrios de la villa & 2.000 maravedies \\
- Renta de la carnicería del concejo & 3.063 mrs. y 2 din. \\
- De un fumazgo del año 1393, la mitad & 549 maravedies \\
- Renta del peso de concejo dos tercios & 203 mrs. y 2 corn. \\
- Renta de la escribanía del concejo de 8 meses & 575 maravedies \\
\hline
\end{tabular}

En la cuenta de este mayordomo los principales ingresos provienen de las rentas concejiles: carnicería $(35,5 \%$ de los ingresos), cuezas $(13,1 \%)$, escribania de concejo $\left(6{ }^{\prime} 6 \%\right)$, peso del concejo $(2,35 \%)$, veladoría $(1,72 \%)$, y "aniellos", en orden de mayor a menor contribución. La imposición directa, en forma de un fumazgo, representó muy poco, sólo un $6,36 \%$.

Pero esta cuenta no es significativa, porque aunque no aparezca en la documentación, parece claro que los ingresos concejiles de ese año tuvieron que provenir de otras fuentes aparte de las indicadas en esa cuenta. Si examinamos los ingresos de uno de los procuradores de 1394, puede verse que las rentas concejiles representaban un porcentaje mucho menor, y era la imposición directa la que procuraba la mayor parte de los ingresos del concejo.

Cuadro 3. Los ingresos del procurador de 1394

\begin{tabular}{lcc}
\hline FUENTE DE INGRESOS & CUANTÍA EN MARAVEDIES & PORCENTAJE \\
\hline Rentas & 4.320 & 11,65 \\
aportación barrios & 28.200 & 76,08 \\
alcance procurador & 530 & 1,42 \\
alcances cogedores monedas & $4.015 ' 8$ & 10,83 \\
\hline
\end{tabular}


Según se desprende de este cuadro, la aportación directa de los barrios, proveniente de alguna derrama de un impuesto, era la fuente fundamental de ingresos de la villa, por ello el análisis de la recaudación de impuestos merece un apartado propio.

\section{UN CAPITUULO ESPECIAL DE LOS INGRESOS: LA RECAUDACIÓN DE IMPUESTOS}

En estas primeras cuentas aparecen varios impuestos que constituian las fuentes de ingresos fundamentales del concejo: monedas, alcabalas, fumazgo y mueble, los dos primeros de carácter real y los dos segundos de carácter concejil. No de todos se encuentra el mismo nivel de información, de forma que no se puede realizar un estudio bien equilibrado de cada una de ellos.

En la primera de las cuentas aparece la recaudación de un fumazgo ${ }^{34}$, impuesto que se encuentra en años posteriores y que después se convertirá en una de las fuentes rutinarias de ingresos de la villa. Era una contribución que pagaban los hogares, y que se cargaba con una cantidad fija. En 1386 se pidieron 4 maravedíes por cada hogar y se recaudó en total 2.820 maravedíes, pero otros años se solicitaban otras cantidades, dependiendo de las necesidades para las que se derramara el fumazgo. En efecto, este pecho concejil se derramaba para necesidades específicas. El hecho de ser un impuesto concejil no significaba que se recaudara para necesidades específicamente concejiles, sino que se acudía a él para cubrir gastos de diversa indole, en ocasiones para sufragar las cargas del señor o del rey.

También en 1386 hay noticia de otro de los impuestos concejiles, el mueble, o pecho sobre los ganados de la villa. Al derramarse el impuesto se especificaba con qué cantidad se gravaban los distintos tipos de ganado. Una vez hecha esa valoración se cargaba una cantidad por cada uno de los maravedíes estimados. Ese primer año se cargó a maravedí el maravedí, es decir, por cada maravedí por el que estaban valorados los bienes muebles de una persona habría que pagar un maravedí.

En 1390 aparece la primera referencia a la recaudación de las monedas. Ese año se toma la cuenta de la recaudación de las dos monedas, indicando collación por collación cuántas son las monedas recogidas y la

34 Ver nota 27. 
cuantía recaudada en cada una de ellas. En 1391 hay referencia a 5 monedas y a 6 monedas y en 1392 a una recaudación de 6 monedas. Pero no es hasta 1394 cuando se encuentra una cuenta detallada de la recaudación de las 9 monedas de ese año. Su complejidad merece un estudio más detenido.

La cuenta de estas nueve monedas se inicia con la anotación de Alfons Garcia escribano, quien, sin indicar porqué o con qué derechos, ha recibido en nombre del concejo unas cantidades de los cogedores de las monedas, para después efectuar unos pagos. Las cantidades que recibe son: del cogedor de la collación de S. Miguel 2.508 maravedíes, de los cogedores de la collación de Santa María 1.003, de los de la collación de Santa Olalla 2.965 maravedies y 2 dineros, y de los de la collación de S. Juan 1.938. También recibió 1.163 de las monedas de la aljama de los judíos, y 1.500 del procurador del concejo para pagar a los arrendadores. En total recogió 11.077 maravedíes y 2 dineros.

De esa cantidad Alfons García pagó 5.000 maravedies a García Ferrandes Nieto «por un ponimiento que libro Garcia Ferrandes Pachistre en los maravedíes de las monedas de çinco mill maravedíes e con los mill maravedies que quedaron de paga de los qatorse mill maravedies quel rey enbio demandar al conçeio e que se entregase de los maravedies de las tres monedas çinco mill maravedies". También pagó 6.300 maravedíes a cuatro personas, probablemente los arrendadores de las monedas.

Después de esta primera cuenta, aparecen cuentas parciales de cada uno de las collaciones, indicando lo que los cogedores habían pagado a Alfons Garcia escribano y a otras personas. Finalmente viene desmenuzada la cuenta de cada una de las collaciones, indicando el número de cáñamas y de monedas sencillas, así como la recaudación total de cada collación. A continuación se indican las entregas realizadas por los cogedores de cada collación, las cantidades que no pudieron recaudar y qué vecinos fueron los que no pagaron, y finalmente el alcance final con el concejo, o el remanente que entregan al procurador.

De esta información detallada, llama la atención la manera de distribuir el dinero de cada collación. Todas tienen unos pagos fijos: a Ruy Dias de la Serna «por carta del rey», a Pero Dias Regajal recabdador del conde, al citado Alfons Garcia, a los procuradores, y otros pequeños pagos, entre los que se encuentra su propia soldada o el descuento a los empadronadores.

Ruy Dias de la Serna recibió 7.482 maravedíes, el recaudador del conde 10.040, los procuradores 9.380, y Alfons Garcia escribano 8.415. La soldada de los cogedores fue de 130 maravedíes en las collaciones de S. Juan, 
S. Miguel y Sta. María, y de 250 en la de Santa Olalla, lo que estaba en relación con las cantidades recaudadas, pues mientras en cada una las tres primeras se recaudaron en torno a 9.000 maravedíes, la cantidad de Santa Olalla ascendió a 18.132 maravedíes. En cada una se descontaron 72 maravedíes por los empadronadrores, considerando que había $9 \mathrm{em}$ padronadores, uno por cada moneda, y su valor era de 8 maravedíes la moneda.

Estas cantidades más elevadas entregadas a representantes del Rey, del señor o del concejo, plantean la cuestión de los derechos que asistían a cada una de esas partes para recibir parte del dinero recaudado. Si las monedas eran uno de los derechos reales, la cantidad que recibe el Rey, es una parte pequeña en relación con lo recaudado. El Rey les había "demandado" 14.000 maravedíes, lo que significaba aproximadamente un $30 \%$ de lo recaudado, pero no hay constancia de que se le entregaran esos 14.000. En cambio, quien sale bastante beneficiado de esta derrama es el señor de la villa, cuyo recaudador recibe 10.040 maravedies, aproximadamente un $25 \%$ de la recaudación. No está bien especificado el destino de las cantidades entregadas a los procuradores, pero está claro que no era un dinero para su provecho personal, sino que debía utilizarse para pagos concretos, tal como se especifica en alguna de las cuentas. Cabría preguntarse si pasaba a integrar las arcas concejiles, pero no se encuentra la respuesta en este año, pues faltan las cuentas de los procuradores que reciben el dinero. La otra cantidad sustanciosa, la que recibe el escribano Alfonso García va en buena medida para pagar a los arrendadores.

Una cosa llama la atención del examen detallado de esta cuenta de monedas, y es que la cantidad recaudada para el Rey era pequeña en relación con todo lo que pagaban los vecinos. Entre pagos a arrendadores, cogedores y gastos de diversa índole, se iba bastante dinero. Si esas cantidades entregadas a los procuradores pasan a la hacienda del concejo, el resultado es en cierta medida bastante exitoso para éste, que ve en este impuesto una de sus fuentes de ingresos.

El otro impuesto del que aparecen referencias en diferentes años es el impuesto de las alcabalas. Como impuesto indirecto funcionaba de manera distinta. En 1391 se redactaron las condiciones de su arrendamiento. Este documento permite conocer las alcabalas de esta villa, agrupadas en doce apartados: el vino "cristianego" con el mosto y la uva, el pan y la harina, las cepas y viñas, el pescado fresco junto al salado de mar y de río, "açaeçes", los paños con los picotes y lienzos, la carnecería y los cueros, la pellejería, la lana hilada "e por filar», la madera y el hierro, las bestias $y$ heredades, y finalmente la carne y el vino "judego". 


\section{CONCLUSIÓN}

El examen de estas primeras cuentas del siglo xIV muestra una contabilidad rudimentaria y balbuciente, en consonancia con unas finanzas que están en proceso de organización. La contabilidad concejil tardaría un tiempo en encontrar la forma en la que se desarrollaria durante la mayor parte del siglo xV. En efecto, a lo largo de este siglo se encuentra una clara mejoría en la forma de presentar las cuentas, manifestada en una mayor minuciosidad y sistematización, en línea con lo que ocurría en otras partes de Europa. Coincidiría, como ha indicado B. Chevalier, con la superación de una simple contabilidad de caja, típica de la época de formación de las haciendas municipales ${ }^{35}$.

Tras examinar las cuentas de Paredes de Nava habría que repasar las preguntas iniciales para tratar de comprobar si se han encontrado respuestas; ¿por qué se empezaron a preocupar por anotar las cuentas? ¿se daban en este concejo las circunstancias anotadas al principio como posibles factores para necesitar una contabilidad minuciosa?

Entre los gastos concejiles se encuentra algunos años la reparación de la muralla, pero no era un gasto fundamental como en otros lugares ${ }^{36}$. Sin embargo, antes de la fecha de la primera cuenta conservada es posible que si se vieran obligados a gastos superiores por el mantenimiento de la muralla, pues Paredes de Nava se vio envuelta, como otras villas y ciudades, en las luchas nobiliarias de la primera parte del siglo XIV, y en la lucha fratricida entre Pedro I y Enrique II, porque los señores de la villa formaban parte de alguno de los bandos en lucha.

La autonomía concejil y consecuentemente financiera de la villa no aparece más que cuando hay que derramar un impuesto, de forma que no se puede asegurar que la necesidad de afirmación y mantenimiento de las necesidades concejiles fuera una de las causas para mantener la contabilidad. De hecho, los gastos estrictamente concejiles eran insignificantes, en comparación con los originados por las cargas reales y señoriales. En efecto, los gastos más elevados eran normalmente los pagos que tenian que efectuar a las dos instancias superiores de las que dependían: el

35 B. CheVALIER, art. cit. p. 71.

36 R. Carande, Sevilla, fortaleza y mercado. Sevilla, 1972, 189 y ss., las primeras cuentas de Sevilla, en el siglo XIV, aportan datos de grandes cantidades dedicadas a "labores" en la ciudad. En Namur, como se ha señalado anteriormente en el texto, dos terceras partes de los gastos estaban en relación con las fortificaciones por necesidades militares, Finances et comptabilité urbaines du xille au xvie siecle, 68 . 
rey y el señor de la villa, unos años por causas ordinarias y otros extraordinarias. En la década precedente a las primeras cuentas, esas obligaciones habian sido extraordinarias, como consecuencia de una gravosa multa impuesta por el monarca a los paredeños, que se habían rebelado contra su señor, Felipe de Castro, lo habían asesinado y, en castigo, el monarca, Enrique II, les había exigido el pago de 5.000 doblas de oro ${ }^{37}$.

No hay reflejo del problema financiero que se presentó a la villa para poder pagar tan elevada cantidad, pero no sería arriesgado afirmar que para extraer ese dinero tuvieron que comenzar o definir la fiscalidad, que se muestra ya bastante bien delimitada en las cuentas de 1386. Además, para esa fecha ya había comenzado la política fiscal de los Trastamara, que elevó la presión sobre los pecheros, lo que puede constituir una de las razones por las que en las cuentas aparece la contabilidad de la extracción de las monedas.

Algunas de las cuentas de la derrama de las monedas, se presentan tan complicadas que, sin duda, les debía interesar mantener una contabilidad para evitar problemas. Para los ingresos y gastos puramente concejiles no hubieran necesitado una contabilidad tan minuciosa. Sin embargo, una vez iniciada la costumbre de anotar todos los gastos, las entradas más numerosas, aunque menos cuantiosas, eran las relacionadas con necesidades concejiles. Así en la cuenta de 1393 se verificaron 155 pagos, que constituyeron un total de 8.545 maravedies y 8 dineros.

Por último, habría un aspecto adicional a indicar: la posibilidad del mimetismo, es decir, la posibilidad de que al iniciarse la contabilidad en unos concejos poco a poco esa costumbre se fuera extendiendo a otros. De la misma manera que se puede observar una cierta similitud en la forma de anotarse las cuentas en diferentes partes de Europa, concretamente entre los reinos hispánicos y Francia, no es de extrañar que eso mismo pudiera ocurrir respecto a la costumbre de iniciar los libros de cuentas concejiles, que sencillamente se copiaran de otras partes. En efecto, teniendo en cuenta que no puede considerarse un invento de cada municipio, habría que considerar que algo de ese mimetismo debió de existir.

Sin embargo, concluyendo con la cuestión fundamental, porqué se inicia la contabilidad concejil, la respuesta apunta a los compromisos del concejo con el rey y con el señor, como razón básica para su iniciación y mantenimiento. El interés por la contabilidad minuciosa está en relación

37 J. VALDEÓN, Los conflictos sociales en el reino de Castilla en los siglos xIV y xV, Madrid, 1976, 107 y ss. También en J. C. MARTin CEA, Mundo rural castellano, 45. 
con las obligaciones tributarias hacia el rey, que les interesa que estén claras, que quede constancia de ellas. Como consecuencia se anotan todos los gastos que esa tributacióri acarrea para el concejo (viajes, reuniones, mensajeros, recaudadores, etc.), y a partir de ahí se anota, cada vez más minuciosamente, toda la contabilidad que afecta no sólo a las relaciones del concejo con rey y señor, sino a todos los gastos e ingresos concejiles. Son, pues, exigencias externas las que empujan al concejo a iniciar y mantener una buena contabilidad.

En conclusión, si en el concejo de Paredes de Nava no se encuentran exactamente las mismas causas que en otras ciudades europeas, no sería arriesgado afirmar que en la mayoría de las ciudades y concejos europeos la contabilidad se inició por la presión fiscal debida a conflictos bélicos provocados por diversas causas, y que el inicio de la contabilidad municipal puede considerarse un hito en la evolución no sólo de las finanzas urbanas sino también de la administración de las ciudades y de su desarrollo general. 